\title{
The cumulation of ill health and low agency in socially excluded city dwellers in the Netherlands: how to better identify high-risk/high-need population segments with public health survey data
}

Addi P. L. van Bergen ${ }^{1,2^{*}}$, Annelies van Loon ${ }^{3}$, Stella J. M. Hoff ${ }^{4}$, Judith R. L. M. Wolf ${ }^{5}$ and Albert M. van Hemert ${ }^{2}$

\begin{abstract}
Background: Population segmentation and risk stratification are important strategies for allocating resources in public health, health care and social care. Social exclusion, which is defined as the cumulation of disadvantages in social, economic, cultural and political domains, is associated with an increased risk of health problems, low agency, and as a consequence, a higher need for health and social care. The aim of this study is to test social exclusion against traditional social stratifiers to identify high-risk/high-need population segments.
\end{abstract}

Methods: We used data from 33,285 adults from the 2016 Public Health Monitor of four major cities in the Netherlands. To identify at-risk populations for cardiovascular risk, cancer, low self-rated health, anxiety and depression symptoms, and low personal control, we compared relative risks (RR) and population attributable fractions (PAF) for social exclusion, which was measured with the Social Exclusion Index for Health Surveys (SEI-HS), and four traditional social stratifiers, namely, education, income, labour market position and migration background.

Results: The analyses showed significant associations of social exclusion with all the health indicators and personal control. Particular strong RRs were found for anxiety and depression symptoms (7.95) and low personal control (6.36), with corresponding PAFs of 42 and 35\%, respectively. Social exclusion was significantly better at identifying population segments with high anxiety and depression symptoms and low personal control than were the four traditional stratifiers, while the two approaches were similar at identifying other health problems. The combination of social exclusion with a low labour market position (19.5\% of the adult population) captured $67 \%$ of the prevalence of anxiety and depression symptoms and $60 \%$ of the prevalence of low personal control, as well as substantial proportions of the other health indicators.

(Continued on next page)

\footnotetext{
* Correspondence: avanbergen@ggdhm.nl

'GGD Hollands Midden, Parmentierweg 49, $2316 Z V$ Leiden, The Netherlands

${ }^{2}$ Department of Psychiatry, Leiden University Medical Centre, Albinusdreef 2, 2333 ZA Leiden, The Netherlands

Full list of author information is available at the end of the article
}

(C) The Author(s). 2021 Open Access This article is licensed under a Creative Commons Attribution 4.0 International License, which permits use, sharing, adaptation, distribution and reproduction in any medium or format, as long as you give appropriate credit to the original author(s) and the source, provide a link to the Creative Commons licence, and indicate if changes were made. The images or other third party material in this article are included in the article's Creative Commons. licence, unless indicated otherwise in a credit line to the material. If material is not included in the article's Creative Commons licence and your intended use is not permitted by statutory regulation or exceeds the permitted use, you will need to obtain permission directly from the copyright holder. To view a copy of this licence, visit http://creativecommons.org/licenses/by/4.0/ The Creative Commons Public Domain Dedication waiver (http://creativecommons.org/publicdomain/zero/1.0/) applies to the data made available in this article, unless otherwise stated in a credit line to the data. 
(Continued from previous page)

Conclusions: This study shows that the SEI-HS is a powerful tool for identifying high-risk/high-need population segments in which not only ill health is concentrated, as is the case with traditional social stratifiers, but also a high prevalence of anxiety and depression symptoms and low personal control are present, in addition to an accumulation of social problems. These findings have implications for health care practice, public health and social interventions in large cities.

Keywords: Social exclusion, Social determinants of health, Anxiety and depression, Personal control, Kessler-10, Pearlin mastery scale, Public health monitoring, Population health

\section{Introduction}

Changes in society and demographic trends are putting pressure on our health care system [1]. The ageing population is leading to an increase in multiple morbidities [2], while improved medical treatment is expanding the lifespan of individuals with these health conditions [3]. Over the coming years, health care expenditures in the Netherlands are expected to grow twice as fast as the economy [3]. Households in which social and medical problems accumulate bring in numerous professionalsoften too late-and this puts pressure on municipal finances [3]. It is therefore more important than ever to deploy resources in health care, public health and social care in such a manner that the greatest health gains can be made. To help understand the needs of the population so that governances and services can be better planned and delivered, population segmentation and risk stratification are essential steps.

In Western countries, a strong socioeconomic gradient in health has been observed. Health appears to progressively increase with socioeconomic position [4] and to decrease with higher societal inequality [5]. Traditionally, education, income and profession are used as indicators for socioeconomic status [6], but other social stratifiers have also been used. The World Health Organization summarises the 8 stratifiers that are the most frequently assessed in health inequality monitoring, namely, place of residence (rural, urban, etc.), race or ethnicity, occupation, gender, religion, education, socioeconomic status and social capital or resources (PROGRESS) [7]. We expected that social exclusion (SE) would also be a good or even better candidate than these traditional social factors to describe and analyse the social stratification of health.

According to the World Health Organization (WHO), $\mathrm{SE}$ is rooted in an interplay of dynamic processes at the individual, household, community, country, and global levels. These processes are driven by unequal power relationships and lead to a cumulation of deprivations in the economic, social, cultural and political domains [8, 9]. There is ample evidence that SE impacts health and that, vice versa, ill health exacerbates social exclusion [10]. Mediation and moderation effects may also be in place [11-13]. In fact, health is so intricately linked to
SE that it is considered by some as part and parcel of the concept itself [14].

In this paper, we explored SE as a promising stratifier for both health and low agency. Agency refers herein to the human capability to influence one's functioning and the course of events by one's actions [15]. According to Link and Phelan [16], differential access to resources such as knowledge, money, power, prestige and beneficial social connections is an important, or even the most important, reason why interventions to improve health are consistently less effective in low versus high socioeconomic groups. So-called "high agent" interventions do not work for low socioeconomic groups because participants must use their personal resources or "agency" to benefit [17-19]. Population interventions that require individuals to use a low level of agency, for example, food manufacturers reducing the salt content of bread, smoke-free public places and so-called "nudge" interventions, are likely to be most effective and equitable [17]. At the core of SE lies the inability of persons to participate fully in society and make full use of the benefits that society offers. SE reinforces feelings of powerlessness, alienation, demoralization and lack of self-esteem $[20,21]$. We therefore expected that SE may also be a good candidate to describe and analyse the social stratification of low agency.

To validly measure SE in routine public health monitoring, we previously developed the Social Exclusion Index for Health Surveys (SEI-HS) [22]. The measurement of SE in public health research is still in its infancy, and a generally accepted valid measure has not yet been developed [9]. Limitations related to earlier measures include a limited focus on only one aspect of SE, a lack of conceptual justification of indicator choice, a lack of measurement validation, undue length and unsuitability for monitoring in the general population [21]. The SEI-HS measures SE as a multidimensional concept involving cumulative disadvantages in the social, economic, cultural and political domains. It is based on extensive theoretical and empirical research [23, 24] and has been validated for the general population, as well as for the major non-Western immigrant groups in the Netherlands [25].

The aim of this study was to compare SE, as measured with the SEI-HS, with traditional social stratifiers as 
identifiers for high-risk/high-need population segments. We explored SE as a stratifier for health and low agency that potentially captures the information of most of the known stratifiers in a single measure. Our hypotheses were as follows:

1) SE is a stronger social stratifier than the commonly used social factors of education, income, labour market position and migration background.

2) SE is more strongly associated with low agency than the four abovementioned social factors.

3) Combining SE with one of the social factors will not improve its stratifying ability (as SE is the stronger social stratifier).

A social stratifier is considered to be stronger if it identifies strata with a larger health divide. The relative size of the health divide is measured by the relative risk (RR), and the absolute size is measured by the population attributable fraction (PAF). In epidemiology, the RR is the ratio of two risk estimates, and it is a statistic of choice for the comparison of risks between groups, as it is intuitively meaningful [26]. ${ }^{1}$ The PAF estimates the proportion of the health problem that can be attributed to, or that is associated with, a particular risk factor, and thus represents the maximum health effect that can be achieved if the risk factor could be eliminated. We compared the RR and PAF of the stratifiers to identify at-risk populations for cardiovascular risk (diabetes, high blood pressure, smoking, obesity and inactivity), cancer, low self-rated health, anxiety and depression symptoms and low personal control, and we explored whether SE captures in a single measure the information that is normally obtained by the four abovementioned social factors. Data from the 2016 Public Health Monitor from four major cities in the Netherlands were used to test the hypotheses.

\footnotetext{
${ }^{1}$ While the frequently used odds ratio (OR) is an algebraic transformation of probabilities, the relative risk is intuitively more meaningful. To give an example: suppose that $30 \%$ of men and $10 \%$ of women in a given population have diabetes. The OR of men compared to women in this population is 3.9 , which is calculated as $(0.3 / 0.7) /$ $(0.1 / 0.9)$. The RR of men compared to women is 3.0, which means that diabetes is 3-times as common in men than in women. The latter result is easy to grasp, while the first is quite abstract and difficult to explain to policy makers and practitioners. In practice, the OR is often interpreted as a RR. This is acceptable when the outcome is rare (< $10 \%)$ as the value of OR will not be too different from that of RR. However, as the prevalence increases, the two ratios diverge, and the OR will tend to exaggerate the strength of the association [26]. Hence, we have a preference for the use of RRs in this study.
}

\section{Methods}

\section{Data collection}

The data in this study were collected by the Public Health Services of Amsterdam, Rotterdam, The Hague and Utrecht as part of the Public Health Monitor questionnaire 2016. The population sizes of the four cities ranged from 835 thousand in Amsterdam to 630 thousand, 520 thousand and 340 thousand in Rotterdam, The Hague and Utrecht, respectively. In each city, a stratified sample was drawn from the adult population aged $\geq 19$ in non- institutionalised households based on neighbourhood and age category. Subjects were sent an invitation letter and up to three reminders by mail. The average response rate to the survey was $33.2 \%$. Statistics Netherlands (CBS) enriched the monitoring data with administrative information regarding migration background, standardised household income and household composition.

\section{Measures \\ Dependent variables}

- Health. The following measures were included: - Cardiovascular disease (CVD) risk factors: selfreported general practitioner (GP) diagnosis of diabetes; self-reported GP diagnosis of high blood pressure; current smoking; obesity (BMI 30 or higher based on self-reported height and weight); and inactivity (not meeting the daily recommended 30 min of moderate intensive physical activity on any day of the week).

- Cancer: self-reported GP diagnoses of cancer;

- Anxiety and/or depression symptoms: score 30 or higher on the 10-item Kessler Psychological Distress Scale (K10) versus score < 30 [27];

- Self-rated health: fair or poor versus good or very good.

- Agency. The 7-item Pearlin Mastery Scale was used to measure the extent to which an individual regards his or her life chances as being under his or her personal control rather than fatalistically ruled: low $(<$ $20)$ versus high $(>=20)$ personal control.

\section{Independent variables}

- Social exclusion. Social exclusion (SE) was measured with the Social Exclusion Index for Health Surveys (SEI-HS) [22]. The index consists of 17 items that measure four dimensions of SE: 1) social (limited social participation), 2) economic (material deprivation), 3) political (inadequate access to basic social rights) and 4) cultural (lack of normative integration). The scores were dichotomised into 1) moderate to strong exclusion and 2) some or no 
exclusion. As the cut-off point, we used the 95th percentile score in the 2012 Dutch adult population [22].

- Social stratifiers. The following four social factors were included:

- Educational level: highest completed education (self-report) low, i.e., no schooling or elementary schooling versus low-middle, middle and high schooling;

- Household income: standardised disposable annual household income after payment of income tax and social contributions lower than or equal to $€ 16,100$ versus higher ${ }^{2}$;

- Labour market position: self-reported status low, i.e., unemployed, disabled for work and/or on social assistance, versus "other", i.e., paid labour, retired, housewife/man and/or student; and

- Migration background: mother and/or father born in a non-Western country versus born in the Netherlands and/or other Western countries (source: Statistics Netherlands).

- General characteristics. The following measures were included: sex, age and household composition. Age was treated as a continuous variable. Household composition was divided into four categories: family with children (i.e., living with partner, parent(s) and/ or other adult(s) with children), family without children (ditto without children), single parent family and living alone.

\section{Statistics}

First, we described the demographic composition, health, level of personal control and social stratification of the study population. To account for the complex sampling design and selective non-response, sample weights were calculated by Statistics Netherlands based on a linear model with 9 sociodemographic variables and their interaction terms [28]. For each of the measures, weighted descriptive statistics (percentages or means with standard deviations) were computed, and for the demographic measures, unweighted statistics were also computed.

Second, we estimated the relative risk with a $95 \%$ confidence interval (CI) for each health indicator and personal control by SE, education, income, labour market position and migration background. Complex samples cross tabs with relative risk tests were used. Herein, the RR represents the probability of a health indicator or personal control being present in the exposed group $\left(\mathrm{P}_{\mathrm{SE}+}\right.$ or $\left.\mathrm{P}_{\mathrm{SF}+}\right)$ divided by the probability in the non-exposed group $\left(\mathrm{P}_{\mathrm{SE}^{-}}\right.$ or $\left.\mathrm{P}_{\mathrm{SF}^{-}}\right)$, in which $\mathrm{SE}$ is social exclusion and $\mathrm{SF}$ is one of the social factors; + is present and - is not present. An RR

${ }^{2} € 16,100$ corresponds to the lowest income quintile in the Netherlands (source: Statistics Netherlands). between 3 and 8 was considered strong, that between 1.8 and 3.0 was considered moderate and that between 1.4 and 1.8 was considered modest [26].

Third, we calculated the population attributable fractions from the RRs and the prevalences of SE and social factors (SF) with the following formulas:

$$
\begin{aligned}
& \mathrm{PAF}_{\mathrm{SE}}=\mathrm{P}_{\mathrm{SE}+} *\left(\mathrm{RR}_{\mathrm{SE}}-1\right) /\left(\mathrm{P}_{\mathrm{SE}+} *\left(\mathrm{RR}_{\mathrm{SE}}-1\right)+1\right) . \\
& \mathrm{PAF}_{\mathrm{SF}}=\mathrm{P}_{\mathrm{SF}+} *\left(\mathrm{RR}_{\mathrm{SF}}-1\right) /\left(\mathrm{P}_{\mathrm{SF}+} *\left(\mathrm{RR}_{\mathrm{SF}}-1\right)+1\right) .
\end{aligned}
$$

PAFs and RRs were also calculated for the four dimensions of SE: limited social participation, material deprivation, inadequate access to basic social rights and lack of normative integration.

Finally, we calculated the overlap between SE and the four social factors, explored the contribution of SE to the stratifying power of the social factors and investigated the added value of combining SE with one of the social factors in terms of higher RRs and PAFs. Significance was assumed if there was no overlap between the 95\% CIs.

\section{Results}

\section{General characteristics}

The sample consisted of 18,401 women (55.3\%) and 14 , 884 men (44.7\%), with a mean age of 57.1 years (SD 17.7) (Table 1). Almost half of the respondents lived with a partner and no children (46.4\%), and over onethird (34.5\%) lived alone. In the weighted sample, the mean age was lower, i.e., 44.9 years (SD 17.5), and the proportion living with partners and no children was lower (42.9\%), as was the proportion living alone (22.7\%). Weighted data were used in all subsequent analyses.

Table 1 General characteristics of the study sample, Public Health Monitor $2016(N=33,285)$

\begin{tabular}{lll}
\hline & \multicolumn{2}{l}{$\%$ / mean (SD) } \\
\cline { 2 - 3 } & Unweighted & Weighted $^{\text {a }}$ \\
\hline Demographics & 55.3 & 51.1 \\
$\quad$ Female (\%) & $57.1(17.7)$ & $44.9(17.5)$ \\
Mean age (sd) & & \\
Household composition (\%) & 13.8 & 21.7 \\
${\text { Family with children }{ }^{b}}$ & 46.4 & 42.9 \\
Family without children $^{c}$ & 5.3 & 7.4 \\
Single parent & 34.5 & 22.7 \\
Living alone &
\end{tabular}

a Sampling weights were calculated by Statistics Netherlands based on a linear model with 9 sociodemographic variables and their interaction terms [28]

${ }^{b}$ Living with partner, parent(s) and/or other adult(s) with children; ${ }^{c}$ ditto, without children 
Table 2 Prevalence of health indicators and personal control (weighted ${ }^{a}$ )

\begin{tabular}{ll}
\hline & $\%$ \\
\hline CVD risk factors & 7.0 \\
Diabetes & 14.1 \\
High blood pressure & 25.6 \\
Current smoking & 13.4 \\
Obesity (BMI 30 or higher) & 9.3 \\
Inactivity & 2.8 \\
Cancer & 27.3 \\
Self-rated health fair or poor & 9.4 \\
Anxiety and depression symptoms & 11.9 \\
Low personal control &
\end{tabular}

a Sampling weights were calculated by Statistics Netherlands based on a linear model with 9 sociodemographic variables and their interaction terms [28]

\section{Prevalence of health indicators, personal control, SE and social factors}

Smoking was the most prevalent CVD risk factor, as one in four adults reported smoking (25.6\%). Self-rated fair or poor health (SRH) was reported by $27.3 \%$. We found a low score for personal control in $11.9 \%$ of the adult population and a low score for anxiety and depression symptoms in $9.4 \%$ of the population. (Table 2 ).

One in ten adults were moderately to strongly socially excluded (10.3\%); 9.0\% reported a low educational level; $14.1 \%$ reported being unemployed, disabled for work, living on social assistance and without a paid job, and $31.8 \%$ of the adult population had a non-Western migration background. In the cities of Rotterdam and The Hague, these percentages were generally higher than those in Amsterdam and Utrecht. Only income showed a different pattern, with the highest rates of low income being found in Amsterdam and Rotterdam (Table 3).

\section{Performance of SE as social stratifier}

The RRs and PAFs for SE are listed in Table 4, columns 2 and 3, respectively. All relationships were significant at $\alpha=0.05$. The strength of the associations, however, varied considerably between health indicators. The RR was lowest for cancer (1.31) and highest for inactivity (3.29) and anxiety and depression symptoms (7.95). The PAF for cancer was $3.1 \%$, and that for inactivity and anxiety and depression symptoms was 19.0 and 41.6\%, respectively. The RR for low personal control was 6.36, with a PAF of $35.5 \%$. This outcome signifies that socially

Table 3 Prevalence of social exclusion and other social factors by city (weighted percentages ${ }^{\text {a }}$ )

\begin{tabular}{|c|c|c|c|c|c|}
\hline & Amsterdam & Rotterdam & The Hague & Utrecht & $\overline{\text { TOTAL }}$ \\
\hline \multicolumn{6}{|l|}{ Social Exclusion } \\
\hline \multicolumn{6}{|l|}{ SEI-HS index } \\
\hline Moderate to strong & 8.1 & 12.0 & 13.8 & 7.1 & 10.3 \\
\hline Some or no & 91.9 & 88.0 & 86.2 & 92.9 & 89.7 \\
\hline \multicolumn{6}{|l|}{ Social Risk Factors } \\
\hline \multicolumn{6}{|l|}{ Educational level (self-reported) ${ }^{b}$} \\
\hline Low & 7.4 & 11.9 & 9.5 & 6.9 & 9.0 \\
\hline Not low & 92.6 & 88.1 & 90.5 & 93.1 & 91.0 \\
\hline \multicolumn{6}{|l|}{ Standardised annual household income $e^{c}$} \\
\hline Low: $<16,100$ euro & 26.0 & 25.4 & 22.1 & 23.8 & 24.7 \\
\hline Not low & 74.0 & 74.6 & 77.9 & 76.2 & 75.3 \\
\hline \multicolumn{6}{|l|}{ Labour market position } \\
\hline Low: unemployed, disabled, on social assistance & 12.8 & 16.7 & 15.5 & 10.3 & 14.1 \\
\hline Not low & 87.2 & 83.3 & 84.5 & 89.7 & 85.9 \\
\hline \multicolumn{6}{|l|}{ Migration background } \\
\hline Native Dutch & 49.5 & 52.3 & 48.7 & 68.7 & 52.9 \\
\hline Western migration background & 18.2 & 12.1 & 17.0 & 11.2 & 15.3 \\
\hline Non-Western migration background & 32.2 & 35.6 & 34.3 & 20.1 & 31.8 \\
\hline
\end{tabular}

a Sampling weights were calculated by Statistics Netherlands based on a linear model with 9 sociodemographic variables and their interaction terms [28]

b Low: no or elementary schooling (PO); Not low: general secondary education, primary vocational education (MAVO, LBO); higher secondary education, secondary vocational training (HAVO, VWO, MBO); higher professional education and university (HBO, WO)

"For this question, multiple answers were possible. The answers were categorised hierarchically with" > $20 \mathrm{~h} /$ week paid labour" first, followed by" $1-20$ h/week paid labour" and" retired". Those who checked "I am unemployed/job-seeking", "I am disabled for work" or "I am on social assistance" and did not check one of the former three categories were classified as" unemployed, disabled, on social assistance". The remaining respondents who checked "I am housewife/man" or "I am studying" were classified as "housewife/man or student". Those considered "unemployed, disabled, on social assistance" were subsequently classified as low, and the remaining categories were classified as not low 
Table 4 Relative risk $(95 \% \mathrm{Cl})$ and population attributable fraction for SE and social factors ${ }^{\mathrm{b} c}$

\begin{tabular}{|c|c|c|c|c|c|c|c|c|c|c|}
\hline & \multicolumn{2}{|l|}{$\begin{array}{l}\text { Social exclusion } \\
(10.3 \%)^{a}\end{array}$} & \multicolumn{2}{|c|}{ Low education $(9.0 \%)^{a}$} & \multicolumn{2}{|l|}{$\begin{array}{l}\text { Low household } \\
\text { income }(24.7 \%)^{a}\end{array}$} & \multicolumn{2}{|c|}{$\begin{array}{l}\text { Low labour market } \\
\text { position }(14.1 \%)^{a}\end{array}$} & \multicolumn{2}{|c|}{$\begin{array}{l}\text { Non-Western migration } \\
\text { background }(31.8 \%)^{a}\end{array}$} \\
\hline & $\mathrm{RR}$ & PAF & $\mathbf{R R}$ & PAF & $\mathbf{R R}$ & PAF & RR & PAF & $\mathrm{RR}$ & PAF \\
\hline \multicolumn{11}{|l|}{ CVD risk factors } \\
\hline - Diabetes & $2.25(1.96-2.57)$ & 11.33 & $3.83 \uparrow(3.42-4.28)$ & 20.27 & $1.43 \downarrow(1.27-1.61)$ & 9.66 & $2.12(1.86-2.42)$ & 13.65 & $2.06(1.87-2.28)$ & 25.30 \\
\hline $\begin{array}{l}\text { - High blood } \\
\text { pressure }\end{array}$ & $1.63(1.47-1.81)$ & 6.09 & $2.37 \uparrow(2.17-2.59)$ & 10.96 & $1.03 \downarrow(0.94-1.12)$ & 0.64 & $1.66(1.51-1.83)$ & 8.53 & $1.12 \downarrow(1.03-1.21)$ & 3.63 \\
\hline - Current smoking & $1.58(1.46-1.71)$ & 5.64 & $0.98 \downarrow(0.88-1.08)$ & -0.22 & $1.41(1.32-1.51)$ & 9.27 & $1.51(1.40-1.63)$ & 6.73 & $1.02 \downarrow(0.95-1.09)$ & 0.57 \\
\hline - Obesity & $1.92(1.72-2.14)$ & 8.60 & $2.45 \uparrow(2.22-2.71)$ & 11.57 & $1.34 \downarrow(1.22-1.47)$ & 7.71 & $2.05(1.85-2.26)$ & 12.85 & $1.68(1.54-1.82)$ & 17.72 \\
\hline - Inactivity & $\mathbf{3 . 2 9}(2.92-3.70)$ & 18.99 & $2.71(2.40-3.06)$ & 13.33 & $1.86 \downarrow(1.66-2.08)$ & 17.54 & $\mathbf{3 . 1 1}(2.78-3.50)$ & 22.97 & $2.48 \downarrow(2.24-2.74)$ & 32.01 \\
\hline Cancer & $1.31(1.02-1.69)$ & 3.11 & $1.90(1.53-2.36)$ & 7.46 & $0.82 \downarrow(0.66-1.02)$ & -4.75 & $1.56(1.24-1.96)$ & 7.30 & $0.55 \downarrow(0.44-0.69)$ & -16.68 \\
\hline Low self-rated health & $2.83(2.69-2.99)$ & 15.83 & $2.71(2.57-2.85)$ & 13.33 & $1.71 \downarrow(1.62-1.80)$ & 14.87 & $\mathbf{3 . 0 4}(2.89-3.19)$ & 22.31 & $1.82 \downarrow(1.73-1.92)$ & 20.73 \\
\hline Anxiety /depression & 7.95 (7.19-8.78) & 41.60 & $2.79 \downarrow(2.48-3.14)$ & 13.87 & $2.46 \downarrow(2.21-2.75)$ & 26.52 & $\mathbf{5 . 7 9} \downarrow(5.22-6.43)$ & 40.33 & $2.69 \downarrow(2.42-2.98)$ & 34.93 \\
\hline Low personal control & $6.36(5.87-6.91)$ & 35.49 & $3.17 \downarrow(2.88-3.50)$ & 16.34 & $2.08 \downarrow(1.89-2.28)$ & 20.98 & $4.66 \downarrow(4.28-5.09)$ & 34.06 & $2.08 \downarrow(1.91-2.28)$ & 25.67 \\
\hline
\end{tabular}

excluded adults have a 6.36-fold higher chance of experiencing low personal control than non-excluded adults and that a hypothetical reduction of $35.5 \%$ in the prevalence of low personal control could be achieved if the socially excluded segment of the population were to have the same level of personal control as the rest of the population. An overview of RRs and PAFs is given in Figs. 1a and 2a.

\section{Performance of other social factors}

Table 4 columns 4 to 11 present the RRs and PAFs for each combination of social factors and health indicators. Low educational level showed a strong RR for diabetes (3.83) and moderate RRs for all other health indicators except current smoking, which was not significant. Low labour market position showed strong RRs for inactivity (3.11), low SRH (3.04) and anxiety and depression symptoms (5.79) and moderate RRs for diabetes and obesity. We did not find strong RRs in relation to low household income and non-Western migration background. Moderate RRs were found for inactivity and anxiety and depression symptoms by household income and for diabetes, inactivity, low SRH and anxiety and depression symptoms by non-Western migration background. The RRs for low personal control were strong for low education (3.17) and low labour market position (4.66) and moderate for low income and non-Western migration background. The PAFs showed a similar pattern.

\section{SE compared with other social factors}

Figure 1a confirms that SE had much higher RRs for anxiety and depression symptoms and low personal control than did the four social factors (see also Table 4). These higher RRs resulted in higher PAFs for anxiety and depression symptoms and low personal control (Fig. 2a). The RRs of SE were also higher than the RR for smoking by low education; the RRs for diabetes, high blood pressure, obesity, cancer and low SRH by low income; and the RRs for high blood pressure, smoking and cancer by non-Western migration background. The RRs of SE were lower than the RRs for diabetes and high blood pressure by low education. In all other cases, the RRs of SE were not significantly different from those of the other four stratifiers (Fig. 1a, Table 4).

\section{Dimensions of SE}

The RRs of the four dimension scales of the SEI-HS were found to be significant at $\alpha=0.05$ for all health indicators and low personal control, with two exceptions. Only the RRs of the cultural and political dimensions (inadequate access to basic social rights and lack of normative integration) for cancer were not significant. The social and economic dimensions (limited social participation and material deprivation) tended to show somewhat higher RRs than those for the political and cultural dimensions, especially for anxiety and depression symptoms and low personal control. The RRs and PAFs are shown in Table A1 (Additional file 1).

\section{Overlap SE and social factors and combined effect}

To test the third hypothesis, we examined the overlap between the social factors and SE and the added value of combining SE with one of the social factors. Over onethird of adults with a low labour market position were socially excluded (34.1\%). Moderate to strong social exclusion was also found in at least one in five adults with low education (25.7\%), low household income (21.5\%) or non-Western migration background (20.7\%). Therefore, 


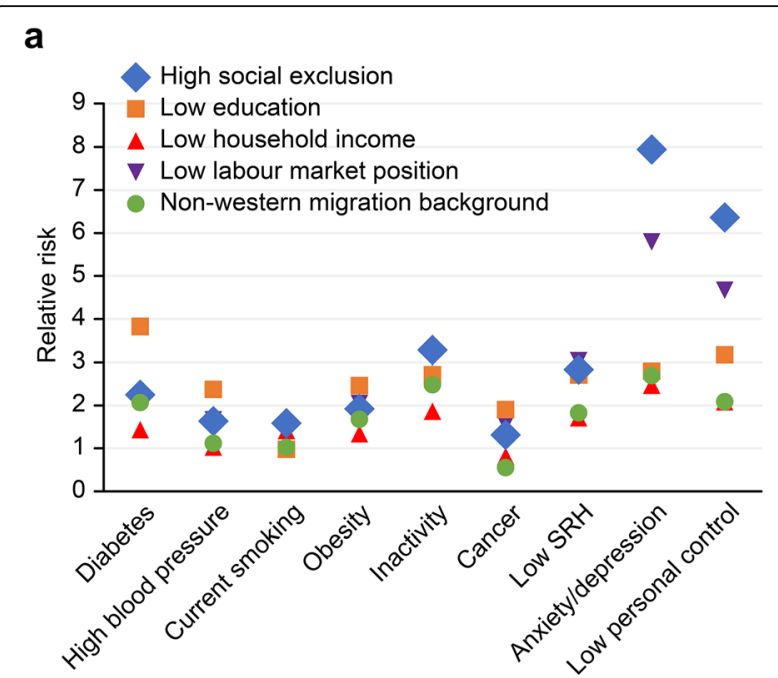

b

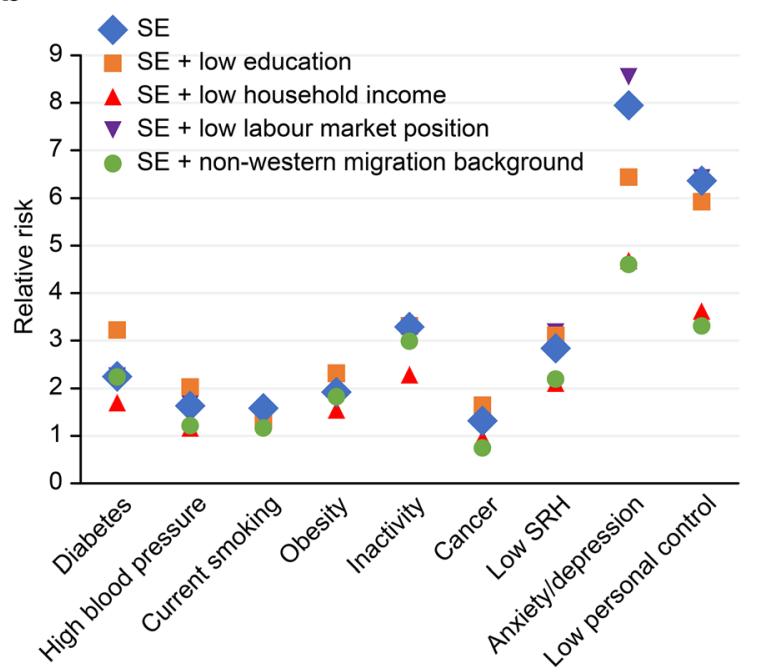

Fig. 1 Relative risks of SE and four social factors, single (Panel a) and combined with SE (Panel b).

Panel a. First orange dot: adults with low education had a 3.8 times higher risk of diabetes than other adults. Last orange dot: adults with low education had a 3.2 times higher risk of low personal control than other adults.

Panel b. First orange dot: adults with low education and/or SE had a 3.2 higher risk of diabetes than other adults. Last orange dot: adults with low education and/or SE had a 5.9 times higher risk of low personal control than other adults

the overlap with SE was considerable, yet the social factors identified mainly non-excluded population groups (66-79\%) (Table A2, Additional file 1).

Figure 3 (and Table A3 Additional file 1) shows that for many health indicators, the RRs were lower in the non-excluded group than in the excluded group. The reference category here consisted of those who were not socially excluded and had no SF present (SE-SF- group). The reference value was set to 1 . Figure $3 a-d$ show that, especially for anxiety and depression symptoms and low personal control, the differences between the RRs were high. Respondents with low education and SE had an RR of 10.53 for anxiety and depression symptoms, while respondents with low education who were not socially excluded had an RR of 2.58, all of whom were compared to the non-exposed group (SE-SF- group) (Fig. 3a). For low labour market positions, the RRs of anxiety and depression symptoms were 15.02 when combined with SE and 5.17 when not (Fig. 3c). A large part of the stratifying power of low education and low labour market position is thus associated with SE. The same pattern can be seen for other health indicators and social factors, with a few exceptions; the $\Delta R R$ s of cancer, obesity and high blood pressure by low education and low labour market position and the $\Delta R R$ of diabetes by low education were not significantly higher with SE than without SE (Table A3 Additional file 1). In all other combinations, the RRs were significantly higher for the $\mathrm{SF}+\mathrm{SE}+$ group than for the $\mathrm{SF}+\mathrm{SE}$-group. It should be noted, however, that although the RRs in the SF + SE- group were generally lower, most of the RRs were significantly higher than 1 (31 out of 36) and would in other studies, with less pronounced results, be seen as relevant (Table A3 Additional file 1).

As shown in Table 5 and Figs. $1 \mathrm{~b}$ and $2 \mathrm{~b}$, we investigated the potential contribution of the social factors to the stratifying power of SE. The panels show for each combination of SE and the social factors the RRs (1b) and PAFs (2b) for ill health and low personal control. The blue diamonds represent the RRs and PAFs of SE alone. In only three cases did the combination of SE with one of the social factors yield a higher RR than that of SE alone. The RRs for diabetes and high blood pressure increased when SE was combined with low education. This was to be expected, as we saw in Fig. 1a that the RRs of low education were significantly higher for diabetes and high blood pressure than the RRs of SE alone. Additionally, the RR for poor SRH increased when SE was combined with a low labour market position (Fig. 2a). In all other cases, combining SE with one of the four social factors resulted in equal or lower RRs (Table 5).

The PAFs were all substantially higher than those for $\mathrm{SE}$ alone, as shown in Fig. 2b. For example, the RR and PAF for anxiety and depression symptoms by SE combined with low labour market position were 8.54 and 59.45 , respectively, while those by SE alone were 7.95 and 41.60, respectively. This combination appears to be the most promising combination for population segmentation. Together, these two stratifiers, SE and low labour market position, identified $67.2 \%$ of the prevalence of anxiety and depression symptoms and $60.4 \%$ of the prevalence of low personal control in the adult 


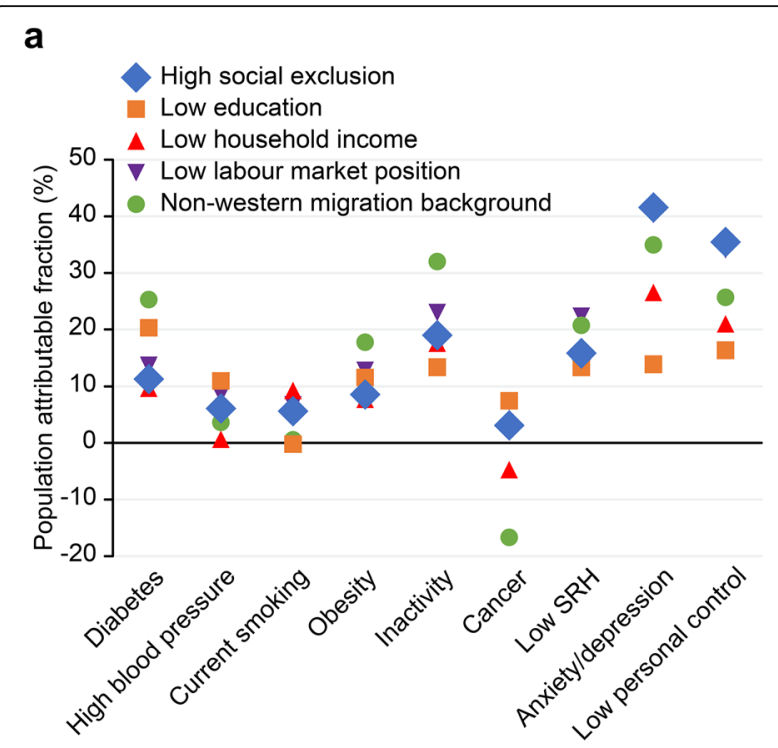

b

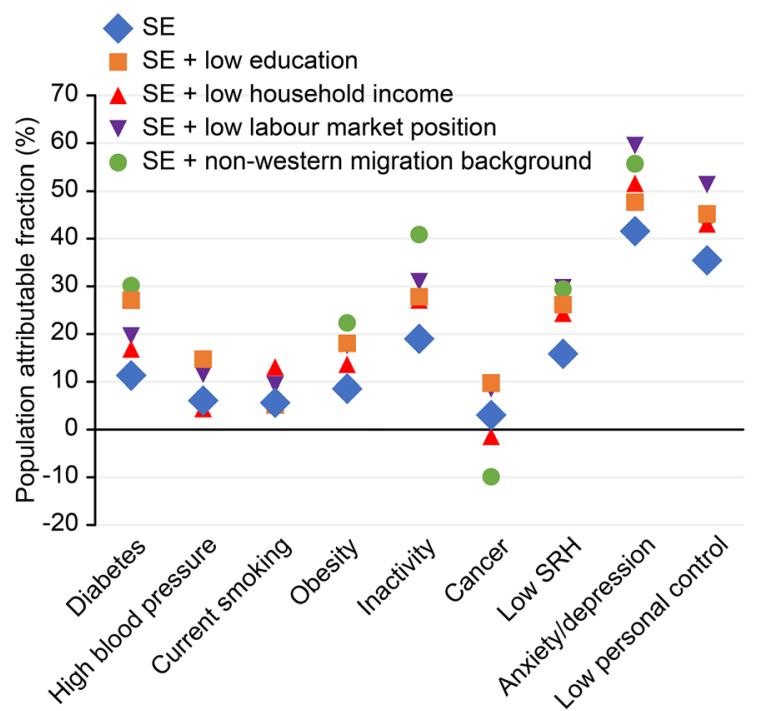

Fig. 2 Population attributable fractions of SE and four social factors, single (Panel a) and combined with SE (Panel b).

Panel a. First orange dot: if adults with low education would have the same risk of diabetes as other adults, the prevalence of diabetes would be reduced by $20 \%$. Last orange dot: if adults with low education would have the same risk of low personal control as other adults, the prevalence of low personal control would be reduced by $27 \%$.

Panel b. First orange dot: if adults with low education and/or SE would have the same risk of diabetes as other adults, the prevalence of diabetes would be reduced with $16 \%$. Last orange dot: if adults with low education and/or SE would have the same risk of low personal control as other adults, the prevalence of low personal control would be reduced by $45 \%$

population of the four study cities (Table 6). Worth mentioning are also the PAFs of inactivity (30.93), low SRH (29.71), diabetes (19.58), obesity (17.57) and high blood pressure (11.49) in this population segment (Table 5).

\section{Discussion}

Our first hypothesis, i.e., that SE is a stronger social stratifier than the commonly used social factors of education, income, labour market position and migration background, was confirmed for all four stratifiers in relation to anxiety and depression symptoms and for low household income and non-Western migration background in relation to the other health indicators. The second hypothesis, i.e., that SE is more strongly associated with low agency than the four social factors was also confirmed. The differences found for low personal control (as an indicator of low agency) were substantial. The third hypothesis, i.e., that combining SE with one of the social factors would not improve its stratifying ability, was confirmed in terms of RRs but not in terms of PAFs.

The study showed a remarkable 7.9-fold higher chance of experiencing anxiety and depression symptoms in socially excluded persons in urban areas of the Netherlands compared to individuals who were not socially excluded, which was significantly higher than that found for low education, low income, low labour market position and non-Western migration background. One might suspect overlapping symptoms between SE and anxiety and depression symptoms, but this was not found to be the case. SE and anxiety and depression are theoretically distinct concepts. Both were measured with validated instruments, namely, the SEI-HS for SE [22] and the Kessler-10 scale for anxiety and depression symptoms [27], respectively. The items of the scales reflect the different underlying concepts. The SEI-HS items ask, for example, about having enough money to heat one's home, missing the pleasure of the company of others, satisfaction with one's housing, giving money to good causes, etc., while the K10 scale items specifically ask about feeling tired, hopeless, restless, depressed, nervous, worthless, etc.. There are no overlapping items.

The K10 scale was originally developed to measure psychological distress, which is a common underlying factor in severe mental illness, in the general population [27] and has since been used to screen for anxiety and, in particular, depression $[29,30]$. A high score on the K10 scale may indicate the presence of an anxiety or a depressive disorder, as well as a response to a specific stressor or demand [31]. Persons in a situation of social exclusion are, by definition, facing multiple problems in different domains of life, including economic and social domains and the lack of access to basic social rights. The emotional, cognitive and psychophysiological manifestations measured with the K10 scale may thus be a reaction to the situation that socially excluded people are 
generally in [31], as well as the result of prolonged exposure to chronic stressors in the form of depression, generalised anxiety and other psychological disorders $[32,33]$. This may explain some of the associations found in this study.

In addition to differential exposure to stress, differences in coping mechanisms and resources may also influence the risk of psychosocial distress. SE citizens are exposed to more stressors, such as financial debts, loneliness, poor housing conditions and other social problems, and their coping mechanisms are also less effective than those of their counterparts. That is why the confirmation of the second hypothesis is crucial. People with a higher level of personal control may appraise themselves as being capable of coping with or controlling problems in their life and therefore may be less physiologically impacted by stressful events and ongoing situations $[34,35]$. As they are more likely to view their health as controllable, they might exercise healthier behaviour and the better management of their health [35]. As almost $50 \%$ of the socially excluded citizens in the four Dutch cities reported low personal control, compared to $5.2 \%$ in the rest of the city population, this finding has implications for health care practice, public health interventions and social care in these cities.

Regarding physical disorders (diabetes, high blood pressure, obesity), lifestyle factors (smoking, inactivity) and low SRH, the first hypothesis was confirmed for low household income and non-Western migration background but not for low education and low labour market position. Low education (no or elementary schooling) and low labour market position (unemployed, disabled for work and/or on social assistance) appeared to be stronger social stratifiers in this population than were low income (lowest quintile disposable household income) and non-Western migration background. In the Netherlands, educational level is commonly used as the standard indicator of socioeconomic status in health research [36]. Our analyses showed that neither the less educated nor the other three social groups are homogeneous. We identified segments within these groups as those with higher and lower risks of ill health related to SE. Educational level, income and occupational status are good predictors of differences in (perceived) health but are not necessarily also the explanatory factors or the direction of solution [37]. Dutch health policies are now mainly aimed at compensating for a lack of knowledge through information, strengthening individual skills and promoting healthy behaviours, which is not enough to reduce health inequities [37].

The third hypothesis was confirmed only in terms of RRs. As SE is the strongest stratifier, combining SE with one of the four social factors did not lead to an increase in RRs. PAF is dependent not only on RR but also on the prevalence of exposure in the population. The proportion of people with SE and/or, for example, low education (16.7\%) or low labour market position (19.4\%) is of course higher than with SE alone $(10.3 \%)$. The choice of whether to target a small group with a high RR or a larger population segment with a lower RR will depend on policy goals, opportunities and political values [38]. In-depth analyses per city can provide guidance here. From a population health perspective, one should consider the potential impact on those with different levels of risk for disease within a population, including those in underrepresented or underserved groups [39].

\section{Implications for policy, practice and research}

We see a number of ways in which health care practice, public health interventions and social care services could be adapted to realise health gains for this population segment based on disease patterns and characteristics that influence the interaction with health and care services.

The first direction is taking agency into account in health care, public health and social care. In health care, a tailor-made and pro-active approach informed by data [40] could make a difference for persons with low agency, as could patient-centred care [41]. A promising development is DIABLEND, which is an integrated approach utilised in two deprived neighbourhoods in The Hague for personalised lifestyle optimisation in people with type-2 diabetes [42]. In public health, the focus for this group should be on the development and implementation of interventions that require little agency and explicitly enhance self-esteem and effective coping mechanisms [17, 43, 44] and increase social support as an important contributor to feelings of personal autonomy [45]. Good examples here are the Amsterdam Healthy Weight Programme that promotes a healthy food environment in which the healthy choice becomes the easy choice [46] and the municipality of Utrecht facilitating local support groups working together on building self-confidence, self-determination, healthy social relationships, meaningful roles and skills [47]. In social care too, agency should not be taken for granted. Pathways to Empowerment (Krachtwerk) is a good example, of a programme that is successfully applied in social and women's shelters in the G4. This programme aims to improve the quality of the daily lives of persons who experience loss of control in their lives by focusing on their strengths and stimulating their personal agency, participation in society, and self-direction in life [48].

A second direction is addressing the convergence of health and social problems in this population segment. Cross-domain working is still in its infancy and in 


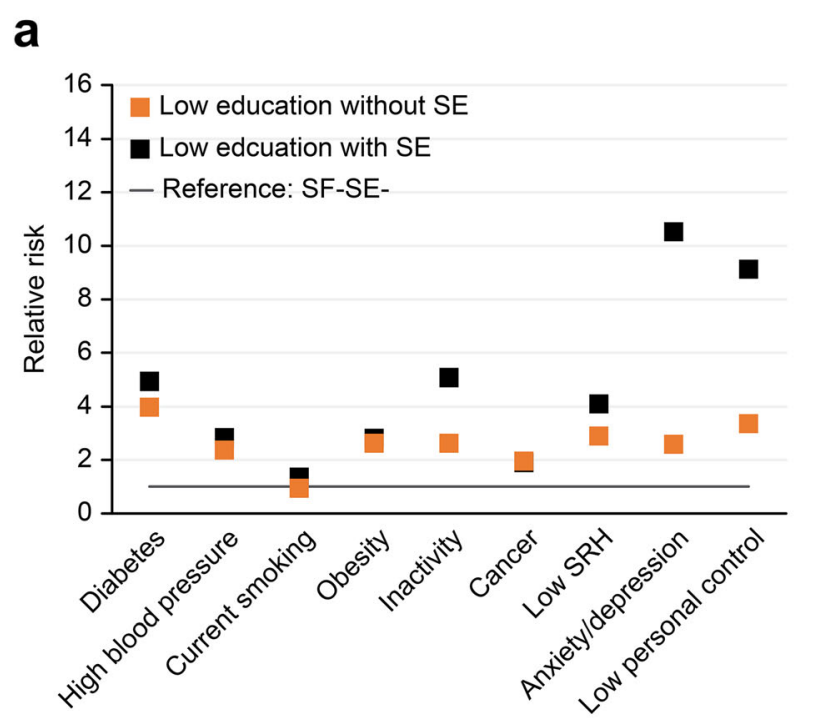

C

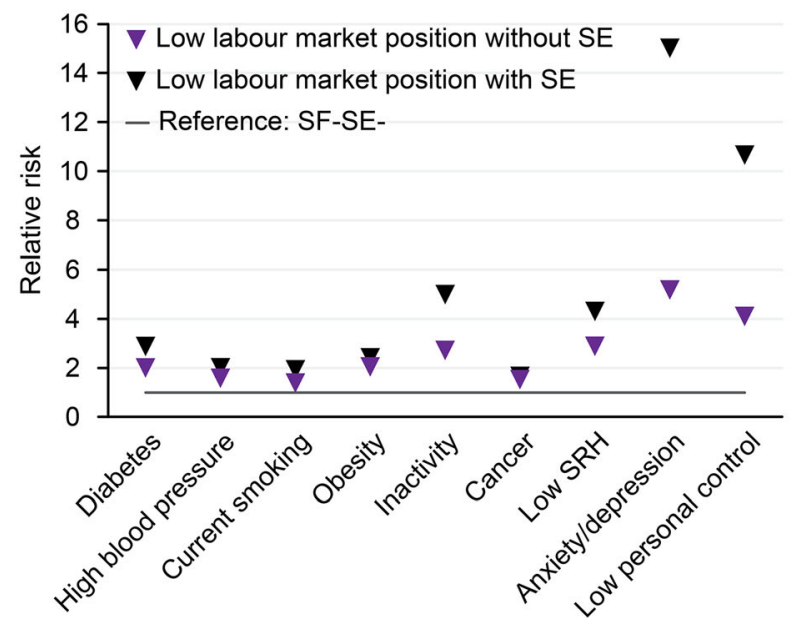

b

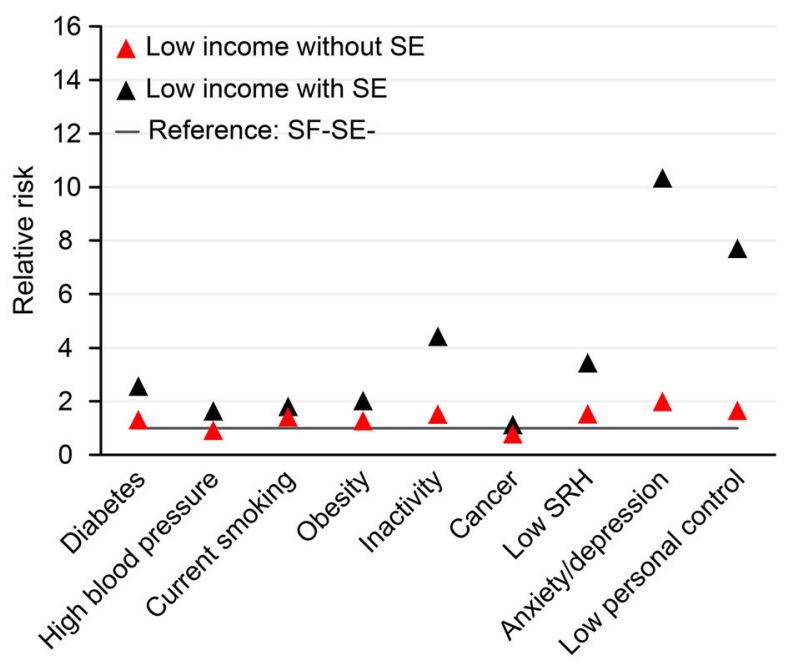

d

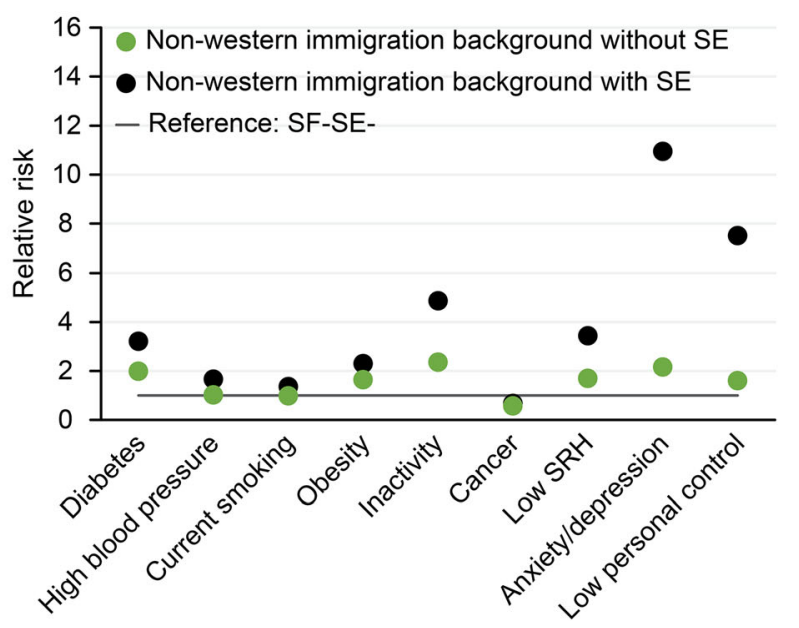

Fig. 3 Relative risk by social factor SF, without and with SE, compared to the non-exposed group (SF-SE- group)

practice, it is hard to get off the ground [3]. The Dutch programme" The Right Care in the Right Place" sets an example by advocating a different perspective on sickness and health, with more focus on what people need to be able to function and less on what the care system has to offer, starting with people's capabilities, vitality, resilience and wishes [3]. A good example is the introduction of Powerful Basic Care (Krachtige Basiszorg) within deprived areas in the G4 [49]. In social care, more attention should be given to health and health promotion.

A third direction is paying more attention to upstream policies at the meso and macro levels. SE is not just an individual problem. Lack of social cohesion, discrimination and stigma, deprived neighbourhoods, complex bureaucratic procedures, individualization, high demands on people's self-reliance and lagging social benefits are all factors that affect SE and health. The issue we should pursue is how to ensure that people who are on social benefits, and those we are unemployed or disabled and cannot work, can participate fully in our society; i.e., how do we make our institutions inclusive and build up self-respect and agency instead of distorting these capabilities? A good example here is the application of scientific evidence, e.g., on Mobility Mentoring ${ }^{\circ}$, to create stress-sensitive services within the municipality of Utrecht [47]. Room for future social experiments and comparative research is needed.

The fourth and last direction is not forgetting those who have already fallen through the cracks of society, 
Table 5 Relative risk $(95 \% \mathrm{Cl})$ and population attributable fraction for combinations of SE and social factors ${ }^{\mathrm{b}} \mathrm{c}$

\begin{tabular}{|c|c|c|c|c|c|c|c|c|c|c|}
\hline & \multicolumn{2}{|l|}{ SE $(10.3 \%)^{a}$} & \multicolumn{2}{|c|}{$\begin{array}{l}\text { SE + low education } \\
(16.7 \%)^{a}\end{array}$} & \multicolumn{2}{|c|}{$\begin{array}{l}\text { SE + low household } \\
\text { income }(29.0 \%)^{a}\end{array}$} & \multicolumn{2}{|c|}{$\begin{array}{l}\text { SE + low labour market } \\
\text { position }(19.4 \%)^{a}\end{array}$} & \multicolumn{2}{|c|}{$\begin{array}{l}\text { SE + non-Western } \\
\text { migration background } \\
(34.8 \%)^{a}\end{array}$} \\
\hline & RR & PAF & RR & PAF & RR & PAF & $\mathbf{R R}$ & PAF & $\mathbf{R R}$ & PAF \\
\hline \multicolumn{11}{|l|}{ CVD risk factors } \\
\hline - Diabetes & $2.25(1.96-2.57)$ & 11.33 & $3.22 \uparrow(2.89-3.58)$ & 27.07 & $1.70 \downarrow(1.52-1.89)$ & 16.83 & $2.25(2.01-2.53)$ & 19.58 & $2.24(2.03-2.47)$ & 30.14 \\
\hline $\begin{array}{l}\text { - High blood } \\
\text { pressure }\end{array}$ & $1.63(1.47-1.81)$ & 6.09 & $2.03 \uparrow(1.87-2.20)$ & 14.69 & $1.16 \downarrow(1.07-1.26)$ & 4.41 & $1.67(1.53-1.82)$ & 11.49 & $1.21 \downarrow(1.12-1.30)$ & 6.76 \\
\hline - Current smoking & $1.58(1.46-1.71)$ & 5.64 & $1.32 \downarrow(1.23-1.42)$ & 5.15 & $1.52(1.42-1.61)$ & 13.01 & $1.53(1.43-1.63)$ & 9.31 & $1.16 \downarrow(1.09-1.24)$ & 5.28 \\
\hline - Obesity & $1.92(1.72-2.14)$ & 8.60 & $2.31(2.12-2.52)$ & 18.00 & $1.54 \downarrow(1.41-1.68)$ & 13.60 & $2.10(1.92-2.29)$ & 17.57 & $1.82(1.68-1.98)$ & 22.29 \\
\hline - Inactivity & $\mathbf{3 . 2 9}(2.92-3.70)$ & 18.99 & $3.30(2.96-3.67)$ & 27.80 & $2.28 \downarrow(2.05-2.54)$ & 27.11 & $3.30(2.96-3.68)$ & 30.93 & $2.98(2.69-3.30)$ & 40.83 \\
\hline Cancer & $1.31(1.02-1.69)$ & 3.11 & $1.64(1.36-1.98)$ & 9.74 & $0.95(0.79-1.15)$ & -1.41 & $1.48(1.22-1.81)$ & 8.60 & $0.75 \downarrow(0.61-0.90)$ & -9.92 \\
\hline Low self-rated health & $2.83(2.69-2.99)$ & 15.83 & $3.11(2.96-3.27)$ & 26.14 & $2.11 \downarrow(2.00-2.22)$ & 24.30 & $3.18 \uparrow(3.02-3.34)$ & 29.71 & $2.20 \downarrow(2.08-2.31)$ & 29.40 \\
\hline Anxiety /depression & 7.95 (7.19-8.78) & 41.60 & $6.44 \downarrow(5.78-7.18)$ & 47.67 & $4.68 \downarrow(4.17-5.25)$ & 51.63 & $\mathbf{8 . 5 4}(7.63-9.57)$ & 59.45 & $4.60 \downarrow(4.10-5.17)$ & 55.66 \\
\hline Low personal control & $6.36(5.87-6.91)$ & 35.49 & $5.92(5.44-6.45)$ & 45.20 & $3.61 \downarrow(3.31-3.95)$ & 43.09 & $6.42(5.89-6.99)$ & 51.30 & $3.31 \downarrow(3.03-3.61)$ & 44.56 \\
\hline
\end{tabular}

${ }^{a}$ Weighted prevalences, population 19 years and older, G4, 2016

${ }^{b}$ In italic if not significant at $a=0.05$ and bold if RR strong, i.e., between 3 and 8 [26]

c $\downarrow$ RR is significantly lower than the RR of SE alone, i.e., no overlap of $95 \% \mathrm{Cls}$, $\uparrow$ RR is significantly higher than the RR of SE alone

i.e., the homeless, people living in protected and sheltered housing, detainees and undocumented immigrants, all of whom did not participate in this research. It is important to incorporate these groups in regular health care, prevention and social policies to prevent further exclusion.

\section{Strengths and limitations}

This study has some major strengths and limitations. The strong points include the use of a large representative sample, the inclusion of all major lifestyle and health outcomes in terms of mortality and morbidity and the employment of validated instruments to measure social exclusion, anxiety and depression symptoms and personal control. The limitations are as follows. First, as in any cross-sectional study, no causal relations could be examined. The PAFs calculated in this study are largely theoretical and do not necessarily hold in practice. The PAFs herein represent the proportional reduction in overall morbidity or unhealthy behaviour that would occur if the lowest social stratum would experience the same rate as the rest of the population. No rigorous statistical testing took place, as this was not considered relevant for the purpose of the research and the exploratory nature of the study. In addition, confounding has not been taken into account. Our goal was to identify population segments with high levels of ill health and low personal control in a given context. In a different social context, a comparable study could lead to different results. We expect, based on additional analyses per city

Table 6 Prevalence and proportion of ill health and personal control by population segment (\%'s, weighted ${ }^{\mathrm{a}}$ )

\begin{tabular}{|c|c|c|c|c|}
\hline & \multicolumn{2}{|l|}{ SE segment } & \multicolumn{2}{|c|}{ SE + low labour market segment } \\
\hline & Prevalence & Proportion $^{\mathbf{b}}$ & Prevalence & Proportion $^{\mathbf{b}}$ \\
\hline \multicolumn{5}{|l|}{ CVD risk factors } \\
\hline Diabetes & 13.8 & 20.2 & 12.3 & 35.0 \\
\hline High blood pressure & 21.4 & 15.5 & 20.3 & 28.4 \\
\hline Current smoking & 38.2 & 15.3 & 35.5 & 26.9 \\
\hline Obesity (BMI 30 or higher) & 23.5 & 17.6 & 23.0 & 33.0 \\
\hline Inactivity & 24.3 & 26.6 & 20.3 & 43.8 \\
\hline Cancer & 3.6 & 12.8 & 3.7 & 26.1 \\
\hline Self-rated health fair or poor & 64.4 & 24.4 & 59.3 & 43.3 \\
\hline Anxiety and depression symptoms & 42.4 & 47.5 & 31.5 & 67.2 \\
\hline Low personal control & 48.6 & 41.7 & 35.5 & 60.4 \\
\hline
\end{tabular}

a Sampling weights were calculated by Statistics Netherlands based on a linear model with 9 sociodemographic variables and their interaction terms [28]

${ }^{b}$ The proportion of the population with the condition in question, that falls within this segment. For example row 1 Diabetes: of the 174,134 socially excluded adults 24,030 or $13.8 \%$ reported diabetes. The socially excluded population segment thus accounted for $20.2 \%$ of all 118,965 diabetes cases $(24,030 / 118,965)$ 
that are not shown herein but are available from the authors, that the results could be generalised to urban areas with similar socioeconomic characteristics. To allow for future generalizations, factors at the meso and macro levels should be included, such as urbanicity, neighbourhood characteristics, welfare and social policies. In this study, we treated SE, education, income, labour market position and migration background as micro-level characteristics of individuals, while these factors also reflect the underlying social and economic structure. Another limitation of this study is that persons without a fixed address and those living in institutions were not included in the Public Health Monitor, which could have led to an underestimation of the RRs and PAFs. A final limitation is that most health indicators were self-reported. Self-reported measures are prone to social desirability bias and recall bias. There are no concrete indications for differences between social groups in the magnitude or direction of these biases, but it cannot be ruled out.

\section{Conclusions}

This study shows that the SEI-HS is a powerful tool for identifying high-risk/high-need population segments in which not only ill health is concentrated, as is the case with traditional social stratifiers, but also an extremely high prevalence of anxiety and depression symptoms and low personal control are present, in addition to an accumulation of multiple problems in different domains of life. The combination of SE with a low labour market position captured the largest part of the prevalence of anxiety and depression symptoms (67\%) and low personal control $(60 \%)$ in $19.5 \%$ of the population, as well as a substantial portion of other risk factors and negative health outcomes. Significant health gains are likely to be achieved by tailoring health care practice, public health interventions and social care to the needs and capacities of this socially excluded and low labour market group. More in-depth analysis of PHM data is recommended at the local level to sharpen the local profile of the socially excluded population segments per city. In general, more qualitative research, comparative studies and experiments are needed regarding the impact and interaction of meso- and macro-level factors on the triangle formed by $\mathrm{SE}$, health and low agency.

\footnotetext{
Abbreviations

BMI: Body mass index; Cl: Confidence interval; CVD: Cardiovascular disease; GP: General practitioner; K10: 10-item Kessler psychological distress scale; PAF: Population attributable fraction; PROGRESS: Place of residence, race or ethnicity, occupation, gender, religion, education, socioeconomic status and social capital or resources; RR: Relative risk; SD: Standard deviation; SE: Socia exclusion; SEl-HS: Social Exclusion Index for Health Surveys; SF: Social factor; SRH: Self-rated health; WHO: World Health Organization
}

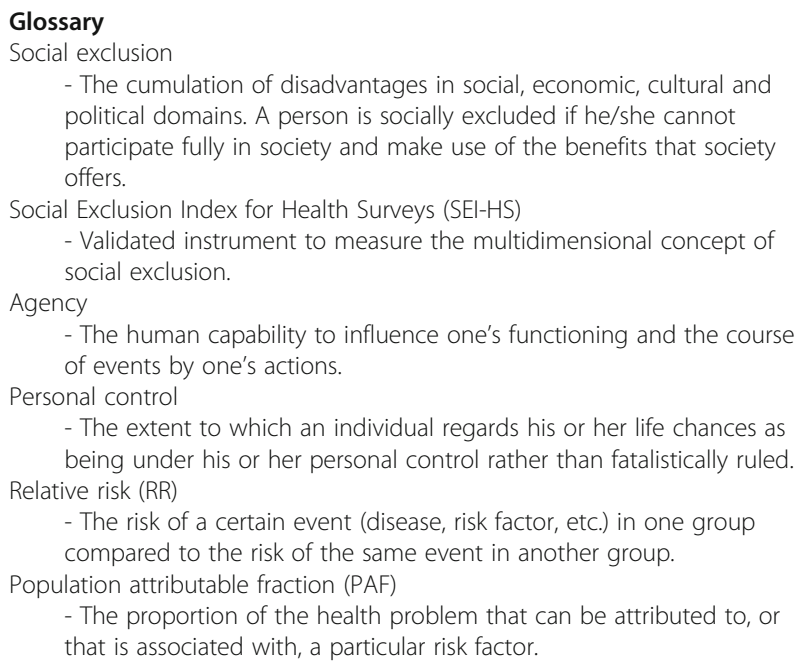

- The extent to which an individual regards his or her life chances as being under his or her personal control rather than fatalistically ruled.

\section{Supplementary Information}

The online version contains supplementary material available at https://doi. org/10.1186/s12939-021-01471-w.

Additional file 1: Table A1. Relative risk (95\% Cl) and PAF for four dimensions of social exclusion. Table A2. Overlap between social exclusion and four social factors (weighted percentages). Table A3. Relative risks $(95 \% \mathrm{Cl})$ for social factors with and without SE and differential effects.

\section{Acknowledgements}

We gratefully acknowledge Henriëtte Dijkshoorn, Gea Schouten, Nasra Karamali and Jessica Bouwman from the Public Health Services of Amsterdam, Rotterdam, The Hague and Utrecht for making available the data used in this study and giving valuable advice on data quality, SPSS syntaxes and other methodological issues.

\section{Authors' contributions}

AvB: Conceptualization, Methodology, Analysis, Writing- Original draft preparation and Editing. AvL, SH, JW: Writing- Review and Editing. $\mathrm{BVH}$ : Conceptualization, Methodology, Writing- Review and Editing. All authors have read and approved the final manuscript.

\section{Funding}

No funding was received for this study.

\section{Availability of data and materials}

The dataset used and analysed in the current study is available from the GGD Rotterdam-Rijnmond (Gezondheidsmonitor@rotterdam.nl) upon reasonable request.

\section{Declarations}

\section{Ethics approval and consent to participate}

The study used secondary data from the Dutch Public Health Monitor 2016. The Medical Ethics Review Committee of the AMC confirmed that under Dutch law, medical ethics approval was not required for the Public Health Monitor 2016 (AMC, W16_166 no. 16.196), as participants were not subjected to any intervention or treatment. In accordance with Dutch law, participants were informed by letter that by filling out the questionnaire, they consented with anonymous use of data for research.

\section{Consent for publication}

Not applicable.

\section{Competing interests}

The authors declare that they have no competing interests. 


\section{Author details}

GGD Hollands Midden, Parmentierweg 49, $2316 Z \mathrm{~V}$ Leiden, The Netherlands. ${ }^{2}$ Department of Psychiatry, Leiden University Medical Centre, Albinusdreef 2, 2333 ZA Leiden, The Netherlands. ${ }^{3} \mathrm{GGD}$ Amsterdam, Nieuwe Achtergracht 100, 1018 WT Amsterdam, The Netherlands. ${ }^{4}$ The Netherlands Institute of Social Research|SCP, Bezuidenhoutseweg 30, 2594 AV Den Haag, The Netherlands. ${ }^{5} \mathrm{Impuls}$, The Netherlands Center for Social Care Research, Radboud University Medical Center, Geert Grooteplein Zuid 21, 6525 GA Nijmegen, The Netherlands.

\section{Received: 1 February 2021 Accepted: 5 May 2021} Published online: 19 July 2021

\section{References}

1. LUMC. Translating innovations > from science to health. Leiden: Leiden University Medical Center (LUMC); 2018.

2. RIVM. Volksgezondheid Toekomst Verkenning 2018. Een gezond vooruitzicht. Synthese. [Dutch Public Health Foresight study 2018. A healthy prospect. Synthesis]. Bilthoven: National Institute for Public Health and the Environment (RIVM); 2018.

3. Taskforce Care in the Right Place. The right care in the right place. Who dares? The Hague: Ministry of Health, Welfare and Sport; 2018.

4. Marmot M, Allen J, Bell R, Bloomer E, Goldblatt P. WHO European review of social determinants of health and the health divide. Lancet. 2012;380(9846): 1011-29. https://doi.org/10.1016/S0140-6736(12)61228-8.

5. Pickett KE, Wilkinson RG. Income inequality and health: a causal review. Soc Sci Med. 2015;128:316-26. https://doi.org/10.1016/j.socscimed.2014.12.031.

6. Shavers VL. Measurement of socioeconomic status in health disparities research. J Natl Med Assoc. 2007;99:1013.

7. WHO. Handbook on health inequality monitoring: with a special focus on lowand middle-income countries. Geneva: World Health Organization; 2013.

8. WHO. Poverty, social exclusion and health systems in the WHO European Region. Copenhagen: WHO Regional Office for Europe; 2010.

9. Popay J, Escorel S, Hernández M, Johnston H, Mathieson J, Rispel L. Understanding and tackling social exclusion. Final report to the WHO commission on social determinants of health from the social exclusion knowledge network. Geneva: World Health Organization; 2008.

10. van Bergen AP, Wolf JR, Badou M, de Wilde-Schutten K, IJzelenberg W, Schreurs $\mathrm{H}$, et al. The association between social exclusion or inclusion and health in EU and OECD countries: a systematic review. Eur J Pub Health. 2019;29(3):575-82. https://doi.org/10.1093/eurpub/cky143.

11. Webber M, Huxley P. Social exclusion and risk of emergency compulsory admission. A case-control study. Soc Psychiatry Psychiatr Epidemiol. 2004; 39(12):1000-9. https://doi.org/10.1007/s00127-004-0836-3.

12. Honey A, Emerson E, Llewellyn G. The mental health of young people with disabilities: impact of social conditions. Soc Psychiatry Psychiatr Epidemiol. 2011:46(1):1-10. https://doi.org/10.1007/s00127-009-0161-y.

13. Foster HM, Celis-Morales CA, Nicholl Bl, Petermann-Rocha F, Pell JP, Gill JM, et al. The effect of socioeconomic deprivation on the association between an extended measurement of unhealthy lifestyle factors and health outcomes: a prospective analysis of the UK biobank cohort. Lancet Public Health. 2018;3(12):e576-85. https://doi.org/10.1016/S2468-2667(18)30200-7.

14. Mathieson J, Popay J, Enoch E, Escorel S, Hernandez M, Johnston H, et al. Social exclusion. Meaning, measurement and experience and links to health inequalities. A review of literature. Geneva: WHO Social Exclusion Knowledge Network; 2008.

15. Agency [https://albertbandura.com/albert-bandura-agency.html]. Accessed 21 Mar 2021.

16. Phelan JC, Link BG, Tehranifar P. Social conditions as fundamental causes of health inequalities: theory, evidence, and policy implications. J Health Soc Behav. 2010;51(1_suppl):S28-40. https://doi.org/10.1177/0022146510383498.

17. Adams J, Mytton O, White M, Monsivais P. Why are some population interventions for diet and obesity more equitable and effective than others? The role of individual agency. PLoS Med. 2016;13:e1001990.

18. McLaren L, McIntyre L, Kirkpatrick S. Rose's population strategy of prevention need not increase social inequalities in health. Int J Epidemiol. 2010;39(2):372-7. https://doi.org/10.1093/ije/dyp315.

19. Capewell S, Graham H. Will cardiovascular disease prevention widen health inequalities? PLoS Med. 2010;7(8):e1000320. https://doi.org/10.1371/journal. pmed. 1000320.
20. Pemberton S, Sutton E, Fahmy E. A review of the qualitative evidence relation to the experience of poverty and exclusion. UK: PSE; 2013. p. 1-60.

21. Cook K. Not measuring up: low-income women receiving welfare benefits. In: Theorising social exclusion. London: Routledge; 2009. p. 65-77.

22. van Bergen AP, Hoff SJ, Schreurs H, van Loon A, van Hemert AM. Social Exclusion Index-For Health Surveys (SEI-HS): a prospective nationwide study to extend and validate a multidimensional social exclusion questionnaire. BMC Public Health. 2017;17(1):253. https://doi.org/10.1186/s12889-017-4175-1.

23. Vrooman J, Hoff S. The disadvantaged among the Dutch: a survey approach to the multidimensional measurement of social exclusion. Soc Indic Res. 2013;113(3):1261-87. https://doi.org/10.1007/s11205-012-0138-1.

24. Jehoel-Gijsbers G. Sociale uitsluiting in Nederland [Social exclusion in the Netherlands]. The Haque: The Netherlands Institute for Social Research|SCP; 2004.

25. van Bergen AP, Loon A, de Wit MA, Hoff SJ, Wolf JR, van Hemert AM. Evaluating the cross-cultural validity of the Dutch version of the social exclusion index for health surveys (SEI-HS): a mixed methods study. PLOS One. 2019;14(11):e0224687. https://doi.org/10.1371/journal.pone.0224687.

26. Schoenbach VJ. Chapter 7: relating risk factors to health outcomes. In: Understanding the Fundamentals of Epidemiology: an evolving text. Chapel Hill: University of North Carolina at Chapel Hill; 2000.

27. Kessler RC, Andrews G, Colpe LJ, Hiripi E, Mroczek DK, Normand S-L, et al. Short screening scales to monitor population prevalences and trends in non-specific psychological distress. Psychol Med. 2002;32(6):959-76. https:// doi.org/10.1017/S0033291702006074.

28. Buelens B. Weging Gezondheidsmonitor 2016 [weighting health monitor 2016]. Heerlen: Statistics Netherlands; 2017.

29. Donker T, Comijs H, Cuijpers P, Terluin B, Nolen W, Zitman F, et al. The validity of the Dutch $\mathrm{K} 10$ and extended K10 screening scales for depressive and anxiety disorders. Psychiatry Res. 2010;176(1):45-50. https://doi.org/10.1 016/j.psychres.2009.01.012.

30. Fassaert T, De Wit M, Tuinebreijer W, Wouters H, Verhoeff A, Beekman A, et al. Psychometric properties of an interviewer-administered version of the Kessler psychological distress scale (K10) among Dutch, Moroccan and Turkish respondents. Int J Methods Psychiatr Res. 2009;18(3):159-68. https:// doi.org/10.1002/mpr.288.

31. Ridner SH. Psychological distress: concept analysis. J Adv Nurs. 2004:45(5): 536-45. https://doi.org/10.1046/j.1365-2648.2003.02938.x.

32. Wheaton B, Montazer S. Stressors, stress, and distress. A handbook for the study of mental health: social contexts, theories, and systems; 2010. p. 171-99.

33. Horwitz AV. Distinguishing distress from disorder as psychological outcomes of stressful social arrangements. Health. 2007;11(3):273-89. https://doi.org/1 $0.1177 / 1363459307077541$

34. Lazarus RS, Folkman S. Stress, appraisal, and coping. New York: Springer publishing company; 1984

35. Roepke SK, Grant I. Toward a more complete understanding of the effects of personal mastery on cardiometabolic health. Health Psychol. 2011;30(5): 615-32. https://doi.org/10.1037/a0023480.

36. Kardal M, Lodder B. De gezonde levensverwachting naar sociaaleconomische status [healthy life expectancy by socio-economic status]. The Hague/Heerlen: Statistics Netherlands; 2008.

37. RVS. Gezondheidsverschillen voorbij. Complexe ongelijkheid is een zaak van ons allemaal [Beyond health differences. Complex inequality is a matter for all of us]. The Hague: Council of Public Health \& Society (RVS); 2020.

38. McLaren L. In defense of a population-level approach to prevention: why public health matters today. Can J Public Health. 2019;110(3):279-84. https://doi.org/10.17269/s41997-019-00198-0.

39. Platt JM, Keyes KM, Galea S. Efficiency or equity? Simulating the impact of high-risk and population intervention strategies for the prevention of disease. SSM - Popul Health. 2017;3:1-8. https://doi.org/10.1016/j.ssmph.201 6.11 .002$.

40. Balicer RD, Shadmi E, Lieberman N, Greenberg-Dotan S, Goldfracht M, Jana $L$, et al. Reducing health disparities: strategy planning and implementation in Israel's largest health care organization. Health Serv Res. 2011;46(4):128199. https://doi.org/10.1111/j.1475-6773.2011.01247.x.

41. van den Muijsenbergh M. Gezondheidsverschillen vragen om persoonsgerichte, integrale zorg door eerstelijns-en publieke gezondheidszorg. Tijdschrift voor Gezondheidswetenschappen. 2019;97(1-2): 36-9. https://doi.org/10.1007/s12508-019-0223-9.

42. Blended lifestyle care for people with type-2 diabetes. Diablend. [https:// www.health-holland.com/project/2020/2020/blended-lifestyle-care-peopletype-2-diabetes]. Accessed 21 Mar 2021. 
43. Capewell S, Capewell A. An effectiveness hierarchy of preventive interventions: neglected paradigm or self-evident truth? J Public Health 2018;40(2):350-8. https://doi.org/10.1093/pubmed/fdx055.

44. Bonmatí-Tomas A, Malagón-Aguilera MC, Gelabert-Vilella S, Bosch-Farré C, Vaandrager L, García-Gil MM, et al. Salutogenic health promotion program for migrant women at risk of social exclusion. Int J Equity Health. 2019;18:139.

45. Smith GC, Kohn SJ, Savage-Stevens SE, Finch JJ, Ingate R, Lim Y-O. The effects of interpersonal and personal agency on perceived control and psychological well-being in adulthood. The Gerontologist. 2000;40(4):45868. https://doi.org/10.1093/geront/40.4.458.

46. IPES-Food. What makes urban food policy happen? Insights from five case studies. International Panel of Experts on Sustainable Food Systems. 2017. www.ipes-food.org.

47. Gezondheid voor iedereen. Volksgezondheidsbeleid Utrecht 2019-2023 [Health for all. Public health policy Utrecht 2019-2023]. Utrecht: Utrecht Municality Public Health; 2019.

48. Wolf JR, Jonker IE. Pathways to empowerment: the social quality approach as a foundation for person-centered interventions. Int J Soc Qual. 2020; 10(1):29-56. https://doi.org/10.3167/JJSQ.2020.100103.

49. Bosman A. Krachtige Basiszorg in Den Haag: kansen voor achterstandswijken [Powerful Basic Care in The Hague: opportunities for disadvantaged neighbourhoods]. Epidemiol Bull. 2020;55:23-7.

\section{Publisher's Note}

Springer Nature remains neutral with regard to jurisdictional claims in published maps and institutional affiliations.

Ready to submit your research? Choose BMC and benefit from:

- fast, convenient online submission

- thorough peer review by experienced researchers in your field

- rapid publication on acceptance

- support for research data, including large and complex data types

- gold Open Access which fosters wider collaboration and increased citations

- maximum visibility for your research: over $100 \mathrm{M}$ website views per year

At $\mathrm{BMC}$, research is always in progress.

Learn more biomedcentral.com/submissions 